\title{
Shedding Light on the Nature of Photoinduced States Formed in a Hydrogen Generating Supramolecular RuPt Photocatalyst by Ultrafast Spectroscopy
}

\author{
Annemarie Huijser ${ }^{\mathrm{a}} \leftarrow$, Qing Pan ${ }^{\mathrm{a} \%}$, David van Duinen ${ }^{\mathrm{a} \S}$, Mads G. Laursen ${ }^{\mathrm{b}}$, Amal El Nahhas ${ }^{\mathrm{c}}$, \\ Pavel Chaberac $^{c}$, Leon Freitag ${ }^{\mathrm{d} \#}$, Leticia González ${ }^{\mathrm{d}}$, Qingyu Konges, Xiaoyi Zhange ${ }^{\mathrm{e}}$, Kristoffer

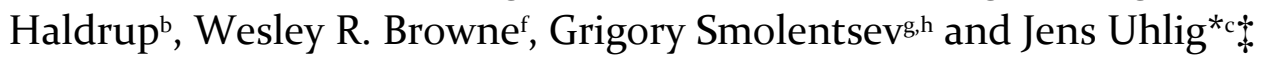 \\ ${ }^{a}$ University of Twente, MESA+ Institute, Optical Sciences and PhotoCatalytic Synthesis groups, PO Box 217, \\ 7500 AE Enschede, The Netherlands. \\ ${ }^{\mathrm{b}}$ Technical University of Denmark, Department of Physics, 280o Kgs Lyngby, Denmark. \\ ${ }^{c}$ Lund University, Department of Chemical Physics, Getingevägen 6o, Lund 2210o, Sweden. \\ ${ }^{d}$ Institute of Theoretical Chemistry, Faculty of Chemistry, University of Vienna, Währinger Str. 17, 109o Vienna, \\ Austria.

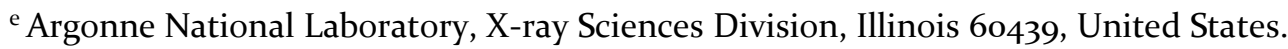 \\ ${ }^{f}$ University of Groningen, Stratingh Institute for Chemistry, Molecular Inorganic Chemistry group, 9747 AG \\ Groningen, The Netherlands. \\ g Paul Scherrer Institute, Villigen 5232, Switzerland. \\ h Smart Materials International Research Center, Southern Federal University of Russia, Rostov-on-Don, 34409o, \\ Russian Federation.
}

\begin{abstract}
Photoinduced electronic and structural changes of a hydrogen generating supramolecular RuPt photocatalyst are studied by a combination of time-resolved photoluminescence, optical transient absorption and x-ray absorption spectroscopy. This work uses the element specificity of $\mathrm{x}$-ray techniques to focus on the interplay between the photophysical and -chemical processes and the associated timescales at the catalytic Pt moiety. We observe a very fast (<30 ps) photoreduction of the Pt catalytic site, followed by a 6oo ps step into a strongly oxidized Pt center. The latter process is likely induced by oxidative addition of reactive iodine species. The oxidized Pt species is long-lived and fully recovers into the original ground state complex at a $>10 \mu$ s timescale. However, the photosensitizing Ru moiety is fully restored at a much faster $\sim 300$ ns timescale. This reaction scheme implies that we may withdraw two electrons from a catalyst that is activated by a single photon.
\end{abstract}

This document is the accepted manuscript version of the following article:

Huijser, A., Pan, Q., van Duinen, D., Laursen, M. G., El Nahhas, A., Chabera, P., ... Uh7ig, J. (2018). Shedding light on the nature of photoinduced states formed in a hydrogengenerating supramolecular RuPt photocatalyst by ultrafast spectroscopy. Journal of Physical Chemistry A, 122(31), 6396-6406. https://doi.org/10.1021/acs.jpca.8b00916 


\section{Introduction}

The impact of increasing atmospheric concentrations of $\mathrm{CO}_{2}$ on life is driving the urgent development of carbon neutral energy conversion approaches. Solar devices are generally considered to be one of the most promising options for environmentally friendly renewable energy. The amount of solar energy reaching the earth in one hour exceeds the annual global energy use $^{1}$, illustrating the potential of converting sunlight into electricity or fuel. A key challenge faced in the use of photovoltaic cells lies in the storage of energy. This constraint has stimulated the development of photocatalytic systems that can convert sunlight into fuel directly, with light-driven generation of $\mathrm{H}_{2}$ from water at the forefront of these efforts.

Amongst various approaches, $\mathrm{H}_{2}$ generating photocatalysts that mimic photosynthesis have been studied intensively in recent years. ${ }^{2-5}$ In these photocatalysts an organometallic photosensitizer is bound chemically to a catalytic moiety via a bridging ligand (intramolecular approach, see Figure 1). This assembly offers key advantages over an intermolecular approach in which the photosensitizer and catalytic moiety units are mixed in solution, relying on diffusion-limited electron transfer to the catalytic moiety to enable proton reduction. ${ }^{6-8}$ An additional component essential in both approaches is the sacrificial agent, regenerating the photosensitizer after lightinduced electron transfer to the catalytic moiety.

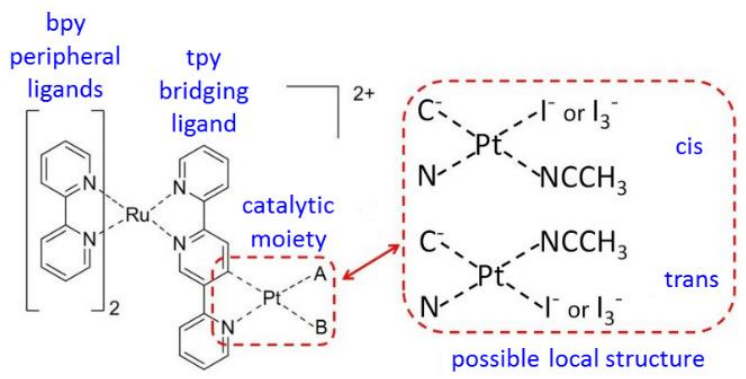

Figure 1. Chemical structure of RuPt in anhydrous acetonitrile. ${ }^{25}$ The right panel illustrates the possible local structures of the Pt catalytic moiety in solution.

Since the first reports on $\mathrm{H}_{2}$ evolving $\mathrm{Ru} / \mathrm{M}(\mathrm{M}=\mathrm{Pd}$ or $\mathrm{Pt})$ organometallic supramolecular photocatalysts independently published by Sakai ${ }^{9}$ and Rau $^{10}$ in 2006 , efforts have been made to develop efficient photocatalysts. To increase their efficiency, control of each of the elementary steps of the photocatalytic hydrogen generation process is essential. Mechanistic insights as those developed here are also relevant for the development of economically attractive $\mathrm{Cu}$ - and Fe-based alternatives. ${ }^{11-17}$ Many of the successful designs originate from Ru-based photocatalysts.

Time-resolved $\mathrm{x}$-ray absorption spectroscopy (XAS) is a powerful method to achieve mechanistic insight into processes occurring at optically dark catalytic metal moieties.
In the case of photocatalysts in particular, it is important to understand photoinduced changes in the oxidation state and coordination geometry of the reaction center. Due to the atomic selectivity of the $\mathrm{x}$-ray probe, this technique can monitor the dynamics at a selected metal center and can thus be applied to probe the essential photoinduced electron transfer step to the catalytic site and the associated atomic rearrangements in real-time. ${ }^{7-21}$ Experiments at synchrotron facilities typically have a time resolution of tens of ps and are well suited to identify the fast and slow dynamics in complex systems. In addition to visualizing early-time excited state processes, $\mathrm{x}$-ray absorption spectroscopy experiments with $\mu$ s time resolution were demonstrated to be capable of tracking reaction intermediates in e.g. catalytic hydrogen evolution. ${ }^{22-24}$ These experiments were performed on a mixture of a photosensitizer, a sacrificial agent and a Co catalyst (i.e. the intermolecular approach) and allowed to detect the $\mathrm{Co}^{\mathrm{I}}$ intermediate species formed by reduction. Importantly, the local structure of the Co catalyst was found to play a critical role in the transiently formed species and the catalytic activity. These studies illustrate the potential of time-resolved $\mathrm{x}$-ray spectroscopy to develop mechanistic understanding of photocatalytic hydrogen generation.

We recently developed a series of new Ru-metal photocatalysts, of which the RuPt derivative (see Figure 1) showed a $\mathrm{H}_{2}$ turnover number of 80 after $6 \mathrm{~h}$ of irradiation at $470 \mathrm{~nm} .{ }^{25}$ An important observation made is that the structure of the catalytic moiety plays a critical role in the early-time photodynamics ${ }^{26}$, which are generally accepted to have a major impact on the photocatalytic performance. ${ }^{27-28}$ Femtosecond optical transient absorption measurements showed important differences between $\mathrm{RuPt}$ and its RuPd analogue. ${ }^{26}$ The spectrotemporal behavior of RuPt is highly complex, indicating a $\sim 1$ ps quenching process of the triplet metal-to-ligand charge transfer ( $3 \mathrm{MLCT}$ ) states localized on the individual ligands, populated after light absorption and intersystem crossing, by a lower-lying $\mathrm{T}_{3}$ state. The behavior of RuPt strongly depends on the excitation wavelength, and the contribution of the $T_{3}$ state is particularly prevalent for excitation at relatively low photon energies. This $T_{3}$ state is unlikely to be localized on the ligands, as it shows a very weak absorption in the blue-ultraviolet region typically associated to ligand-based transitions. The absence of such a $\sim 1$ ps quenching process for the monomeric $\mathrm{Ru}$ precursor suggests that the $T_{3}$ state is associated with the Pt catalytic moiety. A second ultrafast process with $\sim 100$ ps decay time was exclusively observed for RuPt and may thus also be related to the Pt catalytic moiety. ${ }^{26}$

The minor reduction in ${ }^{3} \mathrm{MLCT}$ lifetime and photoluminescence quantum yield observed for RuPt and its RuPd analogue relative to their monomeric Ru precursor could suggest a photoinduced electron transfer from the bridging ligand to the catalytic moiety at a slow $\sim 100$ ns timescale. ${ }^{25}, 29$ An alternative explanation is that the photoluminescence intensities and lifetimes may reflect relative populations of excited states localized at the individual 
ligands (with the state at the bridge potentially delocalized over the catalytic moiety ${ }^{29}$ ), rather than the dynamics of intramolecular electron transfer from the photosensitizer to the Pt moiety. Thus, the photoexcited electron density in the complex may become delocalized over the bridging ligand and the catalyst much faster than these photoluminescence data suggest. To discriminate between these two scenarios, synchrotron-based transient $\mathrm{x}$ ray absorption experiments with ps time resolution have been pursued to identify photoinduced changes in oxidation state and the geometry of the Pt catalytic moiety. The interpretation of the time-resolved $\mathrm{x}$-ray absorption data is supported by time-resolved photoluminescence and transient optical absorption data. An important feature of fs transient absorption spectroscopy is that experiments can be performed at a low $(\mathrm{kHz})$ repetition rate and a relatively long integration time. The low repetition rate is important to avoid a new photoexcitation step before the prior event decaying at a (sub-) $\mu$ s time scale has finalized. Fluorescence upconversion could be an alternative, providing that instead of at a high repetition rate ${ }^{30}$ experiments can be performed at a low repetition rate.

In the ground state $\mathrm{Pt}$ is most likely in its $2+$ oxidation state as $\mathrm{Pt}^{\mathrm{I}}$ species are unstable, and the complex forms the well-known square-planar coordination $\mathrm{Pt}^{\mathrm{II}} \mathrm{d} 8$ complexes are known for. ${ }^{31-32}$ As shown in Figure 1, Pt is coordinated to one $\mathrm{C}$ atom, one $\mathrm{N}$ atom and two I atoms. ${ }^{25}, 33$ Upon dissolving in acetonitrile, one solvent molecule likely becomes coordinated to the Pt atom, substituting one Ianion. ${ }^{25}, 33$ The fourth coordination site remains occupied by an $\mathrm{I}^{-}$anion, as indicated by NMR and elemental analysis. ${ }^{25}$ The position of the $\mathrm{I}^{-}$anion and the solvent molecule may adopt either a cis or a trans configuration (see Figure 1). A number of photochemical reactions involving the bound and the now free $\mathrm{I}^{-}$ions are feasible, such as the formation of $\mathrm{I}_{3}^{-}$at the $\mathrm{I}^{-}$coordination site, or the reaction of Pt with $\mathrm{I}_{2}$ or $\mathrm{I}_{2}{ }^{-}$in an oxidative addition process, forming a hexa-coordinated Pt complex. ${ }^{34-36}$

The aim of this study on RuPt is thus to shed light on the nature of the optically dark $\mathrm{T}_{3}$ state and understand the photochemical processes at the Pt catalytic moiety.

\section{Experimental section Synthesis and steady-state optical characteriza- tion}

The synthesis of RuPt with this bridging structure can lead to the formation of a dinuclear form with one $\mathrm{Ru}$ photosensitizing moiety and one Pt reaction center or to a pentanuclear form with two photosensitizer units and three connected Pt atoms, as described in detail in ref. 25. The current experiments were performed on the dinuclear structure shown in Figure 1. The complexes were dissolved in acetonitrile (Sigma-Aldrich, anhydrous, purity $>99.9 \%$ ) and placed in $1 \mathrm{~cm}$ path length cuvettes for steady-state optical measurements. UV-vis absorption spectra were recorded using a Shimadzu UV-18oo spectrophotometer. Steady-state photoluminescence spectra were obtained using a Horiba Jobin Yvon FluoroMax-4 spectrofluorometer with excitation at $450 \mathrm{~nm}$. Both absorption and photoluminescence spectra were recorded at room temperature.

\section{Time-resolved optical experiments}

Transient absorption (TA) experiments were both pursued in the fs-ps time window and in the ns- $\mu$ s time window. The polarization of pump and probe was set at $54.7^{\circ}$ to avoid anisotropy effects. The fs TA setup ${ }^{29}$ and experimental conditions ${ }^{26}$ were described in detail earlier.

The ns TA experiments were performed with a frequencydoubled electronically delayed and triggered $\mathrm{Nd}: \mathrm{YVO}_{4}$ laser with $3 \mathrm{~mJ} / \mathrm{cm}^{2}, 1 \mathrm{~ns}, 532 \mathrm{~nm}$ as the pump and a supercontinuum probe generated by focusing $800 \mathrm{~nm}, 65 \mathrm{fs}$ laser pulses into a $\mathrm{CaF}_{2}$ crystal. The $\mathrm{CaF}_{2}$ crystal was mounted on a continuously moving stage to avoid thermal damage. The supercontinuum probe signal was dispersed by a grating and measured with a pair of diode arrays. The sample was dissolved to $0.02 \mathrm{mM}$ in anhydrous acetonitrile (Sigma-Aldrich, purity >99.9\%), degassed by dry Ar for 15 minutes and sealed in an airtight 1 mm cuvette.

Photoluminescence decays were obtained by exciting the RuPt sample (o.02 mM in anhydrous acetonitrile, SigmaAldrich, purity $>99.9 \%$, degassed by dry $\mathrm{N}_{2}$ for 30 minutes) with the frequency-doubled output of a Nd-YAG laser $(532 \mathrm{~nm})$. The photoluminescence signal was dispersed by a spectrograph and detected using an amplified CCD camera. The signal acquisition by the camera was gated electronically. The photoluminescence decay was obtained by integrating the recorded emission signal in a spectral window from $550 \mathrm{~nm}$ to $820 \mathrm{~nm}$ at various gate delays. The full width at half maximum of the instrumental response function (Gaussian) was determined to be $4.7 \pm 0.2$ ns. The data were corrected by subtracting the background dark counts.

\section{Steady-state X-ray absorption experiments}

Steady-state $\mathrm{x}$-ray absorption spectra of the Pt L3 edge in the near-edge (XANES) and extended (EXAFS) regime were obtained at the beamline 11-1D-D of the Advanced Photon Source (Argonne, IL, USA) during the same measurement campaign as the transient $\mathrm{x}$-ray spectra discussed below. The RuPt photocatalyst was dissolved in 75-100 $\mathrm{ml}$ batches to a concentration of $0.5 \mathrm{mM} \mathrm{-1} \mathrm{mM} \mathrm{in}$ anhydrous acetonitrile (Sigma-Aldrich, purity >99.9\%), degassed by dry $\mathrm{N}_{2}$ for 30 minutes and kept under constant $\mathrm{N}_{2}$ environment during the measurement. The solution was flown in a round jet with approximately $1 \mathrm{~mm}$ diameter and a flow speed of 1-2 m/s. The total x-ray induced fluorescence was measured by two x-ray diodes equipped with Soller slits and a Z-1 Zn foil of 6 absorption lengths. Details of the setup were reported earlier. 37 The energy was calibrated simultaneously by measuring the $\mathrm{x}$ ray absorption spectra of a metallic Pt foil using the x-ray photons after the sample jet.

Due to the collection mode described in the next section, the steady-state near-edge spectra were collected continuously during the whole experimental campaign, allowing 
intervention once the first accumulative sample damage was observed, typically after 16-18 h of data collection. Steady-state and pump-probe XANES were collected on fully refreshed parts of the jet. During data analysis the spectra were filtered and no data was used in which any (integrated) sample damage was significant. The damaged sample shows a distinct differential feature very different from the pump-probe signals shown in next section. The mode of data collection ensured that the steady-state XANES was collected with significantly higher statistics (approx. $x$ 400o) than the single bunch synchronous pump-probe experiment for the same time interval. The whole sample volume was illuminated for less than 4 minutes. This procedure also ensured the observation of accumulative chemical reaction(s) altering the XANES spectra, if occurring.

\section{Time-resolved X-ray absorption experiments}

Time-resolved x-ray absorption measurements were pursued at beamline 11-1D-D of the Advanced Photon Source (Argonne, IL, USA). Details of the experimental setup were described in the previous section and in earlier publications. ${ }^{37}$ The experiments were conducted in the 24 bunch mode with a bunch separation of $153 \mathrm{~ns}$ and a typical x-ray bunch width (FWHM) of 79 ps. The sample was excited with a $527 \mathrm{~nm}$ laser pulse (5 ps duration, $1.6 \mathrm{kHz}$ repetition rate) focused to a $500 \mu \mathrm{m}$ diameter spot size with an intensity of $\approx 190 \mathrm{~mJ} / \mathrm{cm}^{2}$ per pulse. The excited spot on the flowing liquid jet was probed with the synchronized x-ray bunch at the chosen time delay after laser excitation and the consecutive bunches were spaced in 153 ns time intervals. The bunch-to-bunch normalization allowed the use of the same x-ray bunch during multiple orbits in the storage ring and thus the study of dynamics beyond $3.6 \mu$ s with the same photoexcitation pulse. After approximately $320 \mu \mathrm{s}$, the laser irradiation area flew completely out of the probed region (as observed by following a linear decaying signal and verified by estimations based on flow speed and laser focus diameter) and a number of bunches were used to collect steady-state XANES before the arrival of the next laser pump pulse, which was thus exciting a fully refreshed sample spot. The $x$-ray probe spot was with approximately $50 \mu \mathrm{m}$ (vertical) by $500 \mu \mathrm{m}$ (horizontal) significantly smaller than the pump spot and it is thus reasonable to assume a homogenously excited sample. From the steady-state optical absorption, geometry and pump photon flux, $79 \%$ of the molecules in the probed spot were estimated to be photoexcited, which is necessary due to a competing loss channel at the peripheral ligands. ${ }^{26}$

\section{Data analysis}

The open source program Glotaran ${ }^{38}$ was used for the analysis of the fs-ps TA data. The ns optical TA data was analyzed using methods provided by the python computational package SciPy39 and a newly developed pythonbased analysis suite. The data of multiple scans was aver- aged, sections that showed scattered light from the pump beam were masked and the data was binned into equal 1 nm wavelength bins. The data was then modeled by consecutive exponential decays using a 1 ns instrument response function and a global analysis scheme presented previously..$^{0-42}$ In short, a model is formed that predicts the temporal development of different species using the lifetime parameter as input. For each new set of lifetime parameters, the spectral components were assigned to each species by a least-mean-square optimization to the data. A Nelder-Mead minimization algorithm from the SciPy computational package was used to minimize the $\chi^{2}$ by optimizing the lifetime parameter for the given model, the instrument response function and potential timeoffsets. The decoupled optimization of lifetime parameter and spectral components makes this type of analysis robust against noise in the measured transient spectra.

Steady-state EXAFS were analyzed using the Athena and Artemis packages ${ }^{43}$. The scattering paths were calculated using FEFF 6. The analysis followed the approach recommended in the literature. ${ }^{44-45}$ The absolute energy scale of each scan was calibrated with a simultaneously collected reference foil measurement. The parameters of the model were optimized both in $\mathrm{k}$ and $\mathrm{R}$ space with $\mathrm{k}, \mathrm{k}^{2}$ and $\mathrm{k}^{3}$ weights, leading to fits of very similar quality. Different model molecules were generated with a procedural code and their parameters were in turn refined in Artemis. In addition to this parameter refinement, a number of other structural models were tested by calculating the full multiple scattering with FEFF $8.6^{46}$ and generating/optimizing these structures with a procedural code followed again by an EXAFS refinement. This second procedure was necessary to test a wider range of possible structural alternatives then the simple refinement method permitted.

The XANES scans were energy calibrated using the reference foil, scaled to an edge step of one and summarized for a number of different bunches of the probing x-ray light. These averaged data were compared for different periods of one sample batch and between different sample batches to exclude data from radiation damaged molecules. Once radiation damage was observed, data from this batch was excluded from the analysis. The transient XANES for delay times $<2$ ns, 150 ns and $300 \mathrm{~ns}$ was formed by averaging the signal of single bunches following laser excitation. The transient data for longer delay times used the average of multiple consecutive $\mathrm{x}$-ray bunches (spaced by $153 \mathrm{~ns}$ ).

For modeling of the XANES at the L3 edge, a new python routine was created that combines parametric movement (translation and rotation) of single atoms or whole structural groups with control parameters describing e.g. the electronic configuration and other calculation parameters into input files for FEFF $9 .^{46}$ This routine enables the efficient and restrained optimization of all simulation parameter or, limiting the number of re-calculations, the optimization on a surface span by a few pre-calculations, similar to the approach in FitIt. ${ }^{47}$ By using this method, a 
wide variety of structures and parameters were created, allowing to calculate the XANES and compare these to the experimental spectra. The linear regression was done using the SciPy Statsmodels package..$^{48}$

\section{Results and discussion}

\section{Absorption and fluorescence properties}

Figure $2 \mathrm{a}$ shows the steady-state absorption and photoluminescence spectra of RuPt. The photoluminescence spectrum has been measured for photoexcitation at 450 $\mathrm{nm} /$ The sharp absorption band at ca. $289 \mathrm{~nm}$ is likely due to ligand-centered (LC) $\pi-\pi^{*}$ transitions of the peripheral bpy ligands, and the shoulder around $320 \mathrm{~nm}$ due to LC $\pi-\pi^{*}$ transitions of the bridging 2,2':5,2" terpyridine (tpy) ligand. The broad absorption band centered at $457 \mathrm{~nm}$ likely originates from Ru-based singlet metal-to-ligand charge transfer ( ${ }^{\mathrm{MLCT}}$ ) transitions to the bpy and tpy ligands..$^{25-26}$ In addition, Pt-based MLCT transitions observed earlier between 300-450 $\mathrm{nm}$ possibly contribute to the absorption spectrum. ${ }^{49}$

As intersystem crossing likely occurs very fast in these type of complexes $(<100 \mathrm{fs})^{50-52}$, the photoluminescence centered at ca. $649 \mathrm{~nm}$ is indicative for radiative relaxation from a manifold of lowest 3MLCT states to the ground state..$^{28-29}$ The photoluminescence decay shown in Figure $2 \mathrm{~b}$ has been measured for photoexcitation at 532 $\mathrm{nm}$. The signal has been integrated over nearly the entire emission band from $550 \mathrm{~nm}$ to $820 \mathrm{~nm}$ due to the low molar absorptivity at $532 \mathrm{~nm}$ resulting in a weak emission.
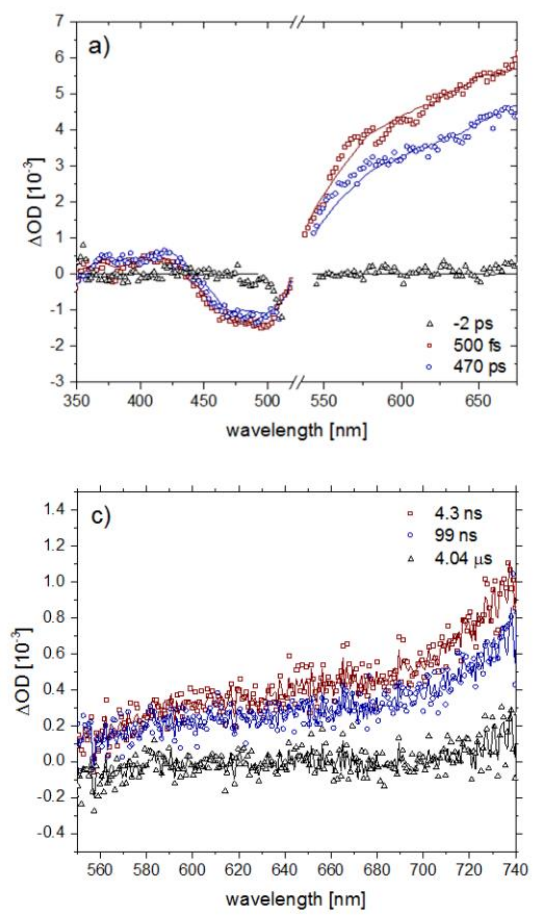
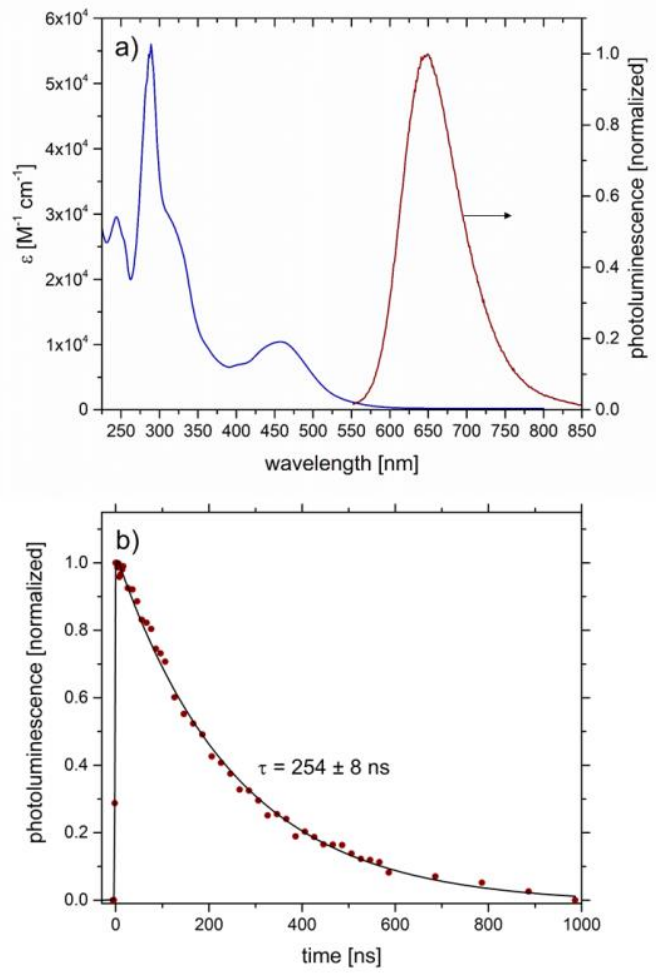

Figure 2. (a) Optical extinction coefficient (blue) and photoluminescence spectra (red) of RuPt in anhydrous acetonitrile and (b) photoluminescence decay integrated from $550 \mathrm{~nm}$ to $820 \mathrm{~nm}$ obtained at $532 \mathrm{~nm}$ excitation (red points), including a fit to a mono-exponential decay function and the resulting lifetime.
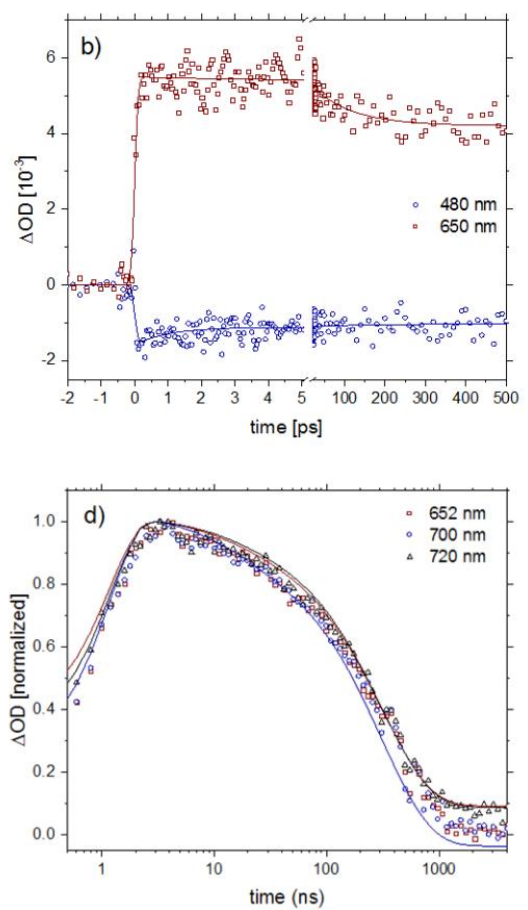

Figure 3. (a) Femtosecond transient absorption spectra of RuPt in anhydrous acetonitrile at $527 \mathrm{~nm}$ excitation and (b) kinetic traces at key wavelengths, with fits based on a sequential model with lifetimes of $980 \pm 184$ fs and $99 \pm 12$ ps included as lines. (c) Nanosecond transient absorption spectra at $532 \mathrm{~nm}$ excitation and (d) kinetic traces at key wavelengths with fits based on a sequential model with lifetimes of $21 \pm 5 \mathrm{~ns}$ and $340 \pm 50 \mathrm{~ns}$ included as lines. The signal raise corresponds to the $1 \mathrm{~ns}$ excitation pulse width. 
The photoluminescence decay is well described by a mono-exponential decay function with a lifetime of $254 \pm 8$ ns.

\section{Transient optical absorption}

To support the interpretation of the time-resolved $\mathrm{x}$-ray absorption data discussed below, transient absorption experiments have been pursued at various pump wavelengths and time windows. Figure za shows the fs transient absorption spectra of RuPt at $527 \mathrm{~nm}$ excitation, with a strong excited state absorption (ESA) band $>530 \mathrm{~nm}$ indicating population of the $\mathrm{T}_{3}$ state. ${ }^{26}$ The negative signal from $450 \mathrm{~nm}-520 \mathrm{~nm}$ is due to ground state bleach (GSB). The weak ESA in the $350 \mathrm{~nm}-450 \mathrm{~nm}$ window suggests a minor population of ${ }^{3} \mathrm{MLCT}$ states. ${ }^{26}$ Figure $3 \mathrm{~b}$ shows the kinetic traces at $480 \mathrm{~nm}$ and $650 \mathrm{~nm}$. The signal at $480 \mathrm{~nm}$ becomes less negative on a $\sim 1$ ps timescale, indicating a potential ${ }^{3} \mathrm{MLCT} \rightarrow \mathrm{T}_{3}$ quenching process, which is more evident for excitation at higher photon energies. Photoexcitation at $516 \mathrm{~nm}$ or $480 \mathrm{~nm}$ (favoring the population of ${ }^{3} \mathrm{MLCT}$ states) also gave a third kinetic component indicating $\sim 5$ ps ${ }^{3} \mathrm{MLCT}_{\text {bpy }} \rightarrow{ }^{3} \mathrm{MLCT}_{\text {tpy }}$ internal conversion competing with vibrational cooling at the bpy ligands. The lack of evidence for this process at 527 $\mathrm{nm}$ photoexcitation with the simultaneous strong ESA for the $T_{3}$ state indicates a non-equilibrated population of excited states and a favored population of the $\mathrm{T}_{3}$ state due to a lower photoexcitation energy. ${ }^{26}$ The broad ESA $>550$ $\mathrm{nm}$ partially decays on a $\sim 100 \mathrm{ps}$ timescale, as illustrated by the kinetic trace at $650 \mathrm{~nm}$. The nature of the $\mathrm{T}_{3}$ state is unknown, although the absence of the $\sim 1$ ps and the $\sim 100$ ps components for the Ru monomeric precursor and the RuPd analogue ${ }^{26}$ seems to suggest an important role of the Pt catalytic moiety. As discussed in the introduction, it is unclear when the photoelectron reaches the $\mathrm{Pt}$ moiety and what is the nature of the electron transfer process.

Transient optical absorption experiments have also been performed in the ns $-\mu$ s time window (Figures $3 \mathrm{c}$ and $3 \mathrm{~d}$, photoexcitation at $532 \mathrm{~nm}$ ). Analogous to the early-time spectra shown in Figure 3a, a strong ESA $>550 \mathrm{~nm}$ is observed. Its spectrotemporal behavior is well described by two timescales of $21 \pm 5 \mathrm{~ns}$ and $340 \pm 50 \mathrm{~ns}$. The latter value is relatively close to the photoluminescence lifetime (Figure $2 \mathrm{~b}$ ), the difference in values may be due to different experimental conditions, in particular the photoexcitation intensity, concentration and degassing conditions. The normalized kinetic traces in Figure $3 \mathrm{~d}$ show that the decay is independent of the ESA wavelength in the probed range. The origin of the $21 \pm 5 \mathrm{~ns}$ and $340 \pm 50$ ns decay times will be discussed below.

\section{Steady-state $\mathrm{x}$-ray absorption}

Figure 4 shows the analysis of the steady-state extended $\mathrm{x}$-ray absorption fine structure (EXAFS) data. The measured EXAFS was modeled by a number of different structures, including amongst other the original RuPt photocatalyst and the complex in which one or both $\mathrm{I}^{-}$anions were replaced by acetonitrile or $\mathrm{I}_{3}{ }^{-}$(see ESI section 1 for a complete list). For each structure the parameters were optimized to yield the best $\chi^{2}$ and the resulting structural parameters were analyzed for feasibility (results with e.g. negative Debye-Waller factors were rejected). In the optimum $\chi^{2}$ associated structural configuration one $\mathrm{I}^{-}$anion is replaced by acetonitrile in the cis configuration (see Figure 1). The right panel of Figure 4 presents this optimized structure and its structural parameters, confirming earlier calculated parameters except for a slightly extended Pt-N1 bond length (1.968 $\pm 0.03 \AA$ vs $2.1 \AA) .25$ This structure was used as the basis for all further calculations. The edge position $\mathrm{E}_{\mathrm{o}}$ corresponding to the oxidation state was left to optimize as part of the fitting process.
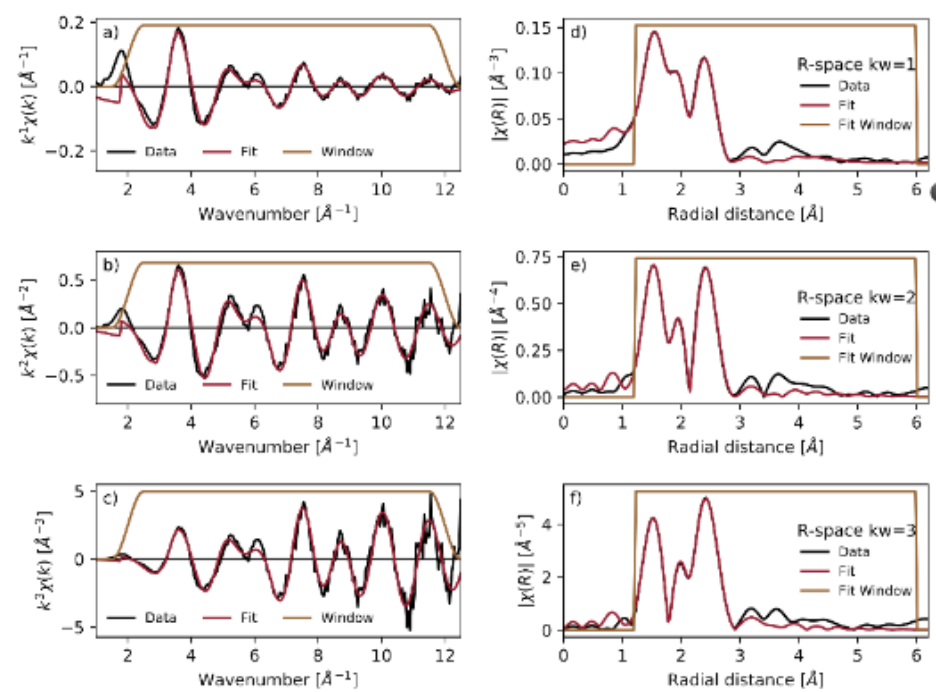

Fit in R-space with $K w=1,2,3$ : $R=0.023, X^{2}=35.4$ Pt-N1:Reff $=1.97 \pm 0.032$ Pt-C1:Reff $=1.98 \pm 0.016$ Pt-N2:Reff $=2.090 \pm 0.0037$ Pt-I:Reff $=2.648 \pm 0.0051$ Pt-C2:Reff $=3.07 \pm 0.018$ Pt-NC:Reff $=3.13 \pm 0.041$

Figure 4. Analysis of extended x-ray absorption fine structure spectrum. Panels (a-c) present the data and fit in k-space for different k-weights, panels (d-f) are data and window in R-space for different k-weights. The fit was performed in R-space with kw $=1,2,3$ and paths up to $3.2 \AA$. The key results and structure are shown in the right panel, with distances given in $\AA$. 


\section{Transient $\mathrm{x}$-ray absorption}

Figure $5^{\mathrm{a}}$ shows transient $\mathrm{x}$-ray absorption spectra of $\mathrm{RuPt}$ at various time delays after $527 \mathrm{~nm}$ photoexcitation. The earliest difference absorption spectrum at 30 ps (Figure 5c) indicates that the Pt catalyst is already reduced at this timescale. The linear regression analysis, i.e. $\log _{e}$ (intensity) vs. time presented in Figure 5 b, shows that the signal intensity decreases on a $930 \pm 100$ ps timescale. The change in shape of the integrated signal suggests that this decay is due to more than a single component. Thus, singular value analysis (SVD) was pursued to elucidate the involvement of different spectral components. Figures $5 \mathrm{~d}-\mathrm{f}$ show the results of this analysis, in which the data matrix $W$, which represents spectra corresponding to different delays, was factorized into $\mathrm{W}=\mathrm{USV}^{*}$. The first two spectral components in $U$ have significant features and are shown in Figure $5 \mathrm{f}$, scaled with the singular values from $\mathrm{S}$ whose values are drawn in Figure $5 \mathrm{~d}$.

These two spectral components have the same shape as the measured spectra at 60 ps and $10 \mu$ s (see Figure 5a) and their time evolution is thus relevant and can be analyzed. The small S value, spectral shape and unphysical time evolution of the third spectral vector suggests that it has to be considered as primarily noise related. The temporal evolution of the first two vectors were again modeled by linear regression (without the 30 ps time point, using only the time points up to $1 \mathrm{~ns}$ ), suggesting a lifetime of $880 \pm 117 \mathrm{ps}$ for SVD component 1 and $630 \pm 270 \mathrm{ps}$ for SVD component 2. The lifetime for the first component and the value determined from the integral in Figure $5 \mathrm{~b}(930 \pm 100 \mathrm{ps})$ match within the error margins. It is apparent that synchronous to the decay of the first spectral component, the growth of the second spectral component halts and is stable within this time window. There are minor changes between the spectra measured at $150 \mathrm{~ns}$ and $300 \mathrm{~ns}$, as well as between the spectra measured at $300 \mathrm{~ns}$ and $10 \mu \mathrm{s}$ (see Figure $5 \mathrm{a}$ ). The first spectral component has no intensity left at these measurement times.

The XANES spectra were modeled using the software package FEFF 9.6.53 with the self-consistent field potentials and multiple scattering algorithm (full parameter set is given in the ESI section 2). In Figure 6a the measured ground state XANES (brown) is shown versus the modeled ground state (black, abbreviated as GS). The ground state model GS reproduces the measured spectrum very well, including the position of the features at $11.575 \mathrm{keV}$ and $11.585 \mathrm{keV}$, while slightly underestimating the total intensity in this region. This behavior has also been found in other publications. ${ }^{53-54}$ Following the methodology established in the literature, the observed and calculated white line intensity for this complex lays between the values typically assigned to $\mathrm{Pt}^{\mathrm{II}}$ and $\mathrm{Pt}^{\mathrm{IV}}$ complexes (see also ESI Figure $S_{7}$ ) and we observe a reduced Fermi parameter in the FEFF modeling, both indicating a partial oxidation of the Pt catalytic center. ${ }^{55-56}$

To model the reduced state (RS) we have taken into account the higher occupancy of the d level (shift of Fermi level by $1.0 \mathrm{eV}$ ) accompanied by a small chemical shift of the spectrum ( $0.3 \mathrm{eV})$, while keeping the same local structure of the complex. It describes the difference spectra measured at 6o ps well (see Figure 6b). The SVD analysis indicates that the transient at 60 ps is a mixture, with ca. $86 \%$ RS and $14 \%$ of the species dominant at $10 \mu \mathrm{s}$. This mixed model describes the shape at $11.568 \mathrm{keV}$ better than
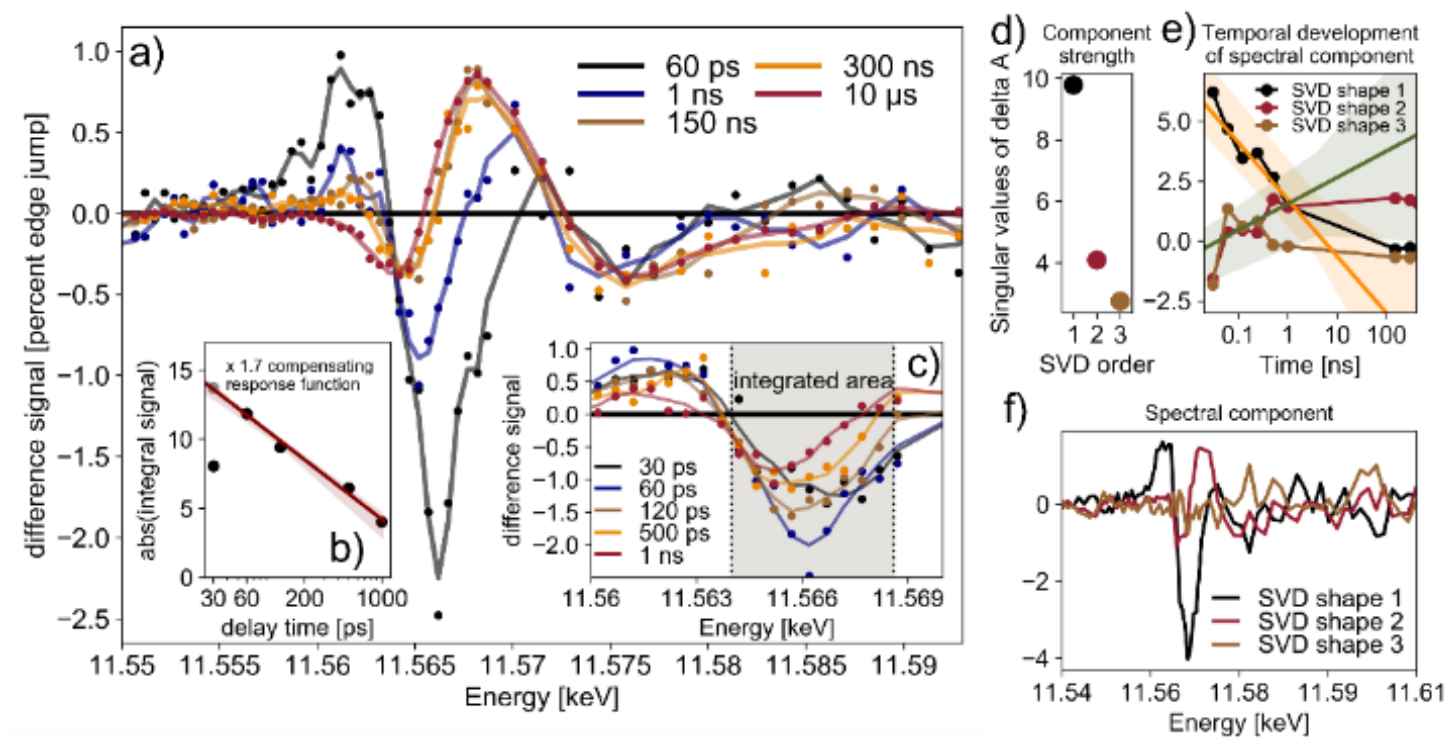

Figure 5. a) Transient x-ray absorption spectra of RuPt in anhydrous acetonitrile at various time delays after $527 \mathrm{~nm}$ photoexcitation (dots, the lines are intended to guide the eye). c) Zoom-in around the Pt L3 absorption edge at early timescales, b) signal intensity integrated over the grey area in c). The linear regression (without the 30 ps point) suggests a lifetime of $930 \pm 100 \mathrm{ps}$. The time point at $30 \mathrm{ps}$ is also shown corrected for the partial overlap of $\mathrm{x}$-ray pulse and pump pulse. d)-f) singular value decomposition (SVD) analysis of the signal matrix. d) The total intensity of the selected SVD component. e) The temporal evolution of the first three spectral components shown in $\mathrm{f}$ ). The linear regression (without the 30 ps time point) suggests a lifetime of $880+/-117$ ps for SVD component 1 and $630+/-270$ ps for SVD component 2 (see text). 
the pure RS model. The white line intensity of this species is comparable with $\mathrm{Pt}^{\mathrm{II}}$ complexes discussed in the literature (see ESI section 7) and shows the clear sign of a reduction compared to the GS..$^{55-56}$ The narrow shape of the difference feature suggests that the primary process we can observe in this time window is a reduction due to the electron transfer and not an oxidation process as would be expected for excitation of a Pt-based MLCT transition (see discussion). 49,61

The long-lived species observed at $10 \mu$ delay is characterized by a higher intensity of the white line (positive transient signal at $11.568 \mathrm{keV}$ ) and a shift of the absorption edge to higher energies (negative signal at the rising edge of the spectrum around $11.564 \mathrm{keV}$, Figure 5a). These are the typical signatures of $\mathrm{Pt}$ oxidation, suggesting a long-lived intermediate. The white line intensity is comparable to the $\mathrm{Pt}^{\mathrm{IV}}$ complexes in the literature (see ESI section 7). ${ }^{55-56}$ It is noteworthy that the observed difference spectrum is broadened further to higher binding energies than can be explained by our proposed model, this indicates the involvement of more than a single oxidation reaction.

To understand the formation of such an intermediate, it is important to point out that during the initial solvation
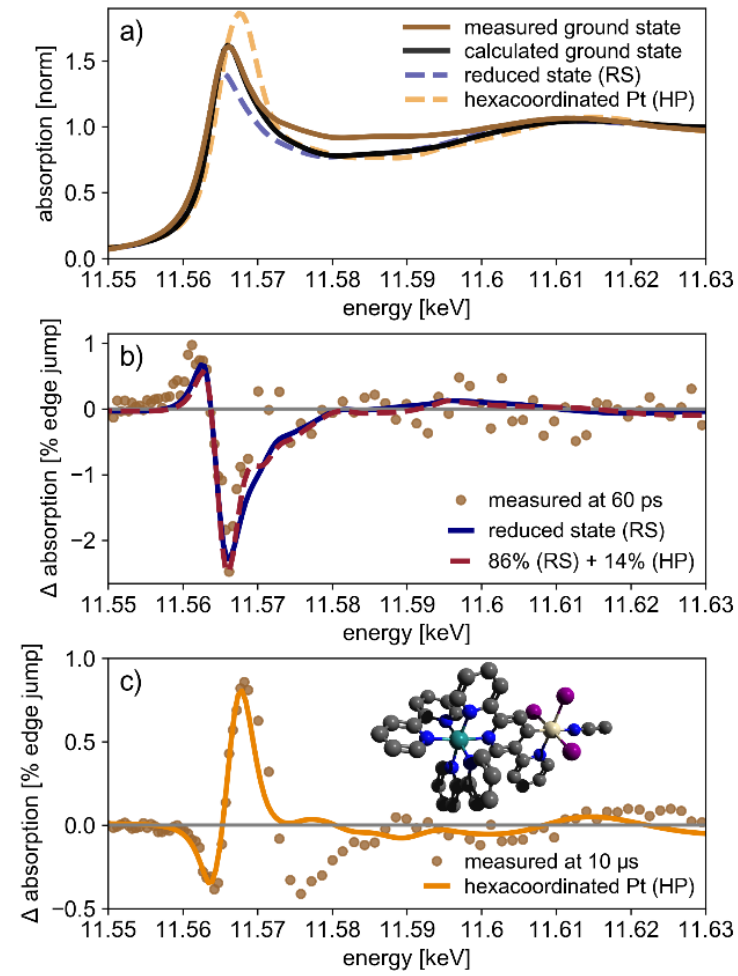

Figure 6. Modeling of XANES data: a) measured ground state spectrum (brown) compared to the calculated ground state spectrum (black) and two excited states RS and HP, b) difference XANES measured at 60 ps delay modeled with a reduction of the platinum site (RS) and a linear combination of RS and HP, c) difference spectrum at $10 \mu$ s (brown), modeled with an oxidative addition of two iodine ions (HP). The inset shows the modeled complex. each RuPt complex releases one $\mathrm{I}^{-}$ion as can be understood by the difference between the crystal structure and the solvated structure discussed above. Thus a large number of $\mathrm{I}^{-}$ions are available in solution and two processes may occur. The first one is the formation of $\mathrm{I}_{3}^{-}$, followed by the substitution of $\mathrm{I}^{-}$by $\mathrm{I}_{3}^{-}$. We have explored the formation of $\mathrm{I}_{3}{ }^{-}$by time-resolved Raman Spectroscopy at $355 \mathrm{~nm}$ in an effort to detect the characteristic $\mathrm{I}_{3}^{-}$enhanced Raman scattering, but these were not observed.

A second process suggested in the literature, combining a strong oxidation with an enhancement of the white line, is oxidative addition. $34-36$, $57-59$ Here $I_{2}$ from the solution oxidizes the complex into a hexa-coordinated $\mathrm{Pt}^{\mathrm{IV}}$ species. We do have a significant amount of $\mathrm{I}^{-}$ions present and it is thus likely that $I_{2}$ is formed and this process is hence possible. The strong oxidation, observed experimentally as the white line enhancement and the failure to observe the characteristic $\mathrm{I}_{3}^{-}$Raman signatures suggest that the latter is the most likely process. We have thus modeled the observed oxidative process at $10 \mu$ with the hexacoordinated Pt species shown in Figure 6c (abbreviated as HP) which shows reasonable agreement with the experiment. Alternative models with different combinations of all components available in solution occupying different bonding sites at various distances and angles (see ESI section 1) give worse agreement with the experimental data.

\section{Discussion}

The population of ${ }^{1} \mathrm{MLCT},{ }^{3} \mathrm{MLCT}_{\mathrm{bpy}},{ }^{3} \mathrm{MLCT}_{\text {tpy }}$ and $\mathrm{T}_{3}$ states depends on the photoexcitation wavelength and is non-equilibrated. More excess energy leads to a larger population of ${ }^{3} \mathrm{MLCT}_{\mathrm{bpy}}$ and ${ }^{3} \mathrm{MLCT}_{\text {tpy }}$ states, and more $\sim 5$ ps ${ }^{3} \mathrm{MLCT}_{\mathrm{bpy}} \rightarrow{ }^{3} \mathrm{MLCT}_{\text {tpy }}$ internal conversion competing with vibrational cooling at the bpy ligands. ${ }^{26}$ This nonequilibrated population of excited states may be responsible for the minor effect of the excitation wavelength on the photoluminescence quantum yield (see ESI section 3 ). The excitation wavelengths used in this work $(527 \mathrm{~nm}$ and $532 \mathrm{~nm}$ ) favor population of the $\mathrm{T}_{3}$ state after photoexcitation of mostly Ru-based ${ }^{1}$ MLCT transitions (see ESI sections 5 and 6) to the bpy and tpy ligands and ultrafast intersystem crossing. ${ }^{.0-52}$ The fs transient optical absorption data indicate that this $\mathrm{T}_{3}$ state is also populated via a $\sim 1$ ps ${ }^{3} \mathrm{MLCT} \rightarrow \mathrm{T}_{3}$ quenching process (Figures za and $\mathrm{b}$ ). The earliest transient $\mathrm{x}$-ray absorption spectrum at $30 \mathrm{ps}$ (Figure 5c) already shows the reduction of the Pt site. Hence, ultrafast population of the $\mathrm{T}_{3}$ state may correspond to reduction of the Pt site.

The subsequent timescale observed by transient optical absorption is $\sim 100$ ps. Note that a comparable $86 \pm 40$ ps decay component, assigned to ground state bleach recovery, has been observed earlier for a related $\mathrm{RuPt}$ complex. ${ }^{60}$ However, the cause of the $\sim 100$ ps component here is likely different, as the ground state bleach signal (Figure $3 \mathrm{~b}$, differential signal at $480 \mathrm{~nm}$ ) does not change at this timescale. The absence of a strong $\sim 100$ ps component in the x-ray data indicates that the associated pro- 
cess is not directly correlated to the Pt moiety. Instead, it may be related to the Ru photosensitizer.

From the time evolution of the $\triangle \mathrm{XAS}$, we observe first a prompt appearance of a species with the signature of reduced Pt, which decays on a $880 \pm 107$ ps timescale (Figures $5 \mathrm{~b}$ and $5 \mathrm{e})$. The $\triangle \mathrm{XAS}$ evolves in both shape and magnitude into the spectrum measured at $10 \mu \mathrm{s}$, indicating that a strongly oxidized species is formed on a $630 \pm 270$ ps timescale, which has a lifetime of $>10 \mu \mathrm{s}$. The formation of the second species does not progress after decay of the reduced species, showing that reduction of $\mathrm{Pt}$ is essential for this reaction. The two timescales and intensities are different, suggesting two separate decay paths from the reduced Pt.

The transient X-ray absorption results suggest two possible alternative scenarios:

1. Reduction of Pt and oxidation of Pt are completely independent processes, occurring at different co-existing RuPt photocatalysts. The first process is induced by electron transfer from the $\mathrm{Ru}$ photosensitizer to the Pt catalytic moiety, while oxidation could be the result of a Ptbased MLCT excitation. ${ }^{49}, 61$

2. The initial Pt reduction step is essential to trigger the oxidation process. Hence, Pt oxidation occurs only for RuPt photocatalysts with reduced Pt centers, formed at the earlier reaction step.

The observation of Pt-based MLCT transitions for Pt(II) complexes ${ }^{49}, 61$ supports scenario 1 . The $\operatorname{Pt}($ III) species formed after photoexcitation in this case will have a weakly axial binding character, forming bonds with the solvent, $\mathrm{I}^{-}, \mathrm{I}_{2}^{-}$or even $\mathrm{I}_{3}^{-}$. The Pt-based MLCT transitions reported in the literature are however in a range of 300$450 \mathrm{~nm}$, suggesting that for $527 \mathrm{~nm}$ excitation used in the transient $\mathrm{x}$-ray experiments scenario 1 is unlikely. This hypothesis is supported by Time-Dependent Density Functional Theory simulations, indicating a dominant contribution from Ru-based MLCT transitions at $527 \mathrm{~nm}$ excitation (see ESI section 6). A minor contribution of Ptbased optical transitions leading to ultrafast oxidation of a small fraction of the Pt moieties is however possible. Further evidence for scenario 2 is provided by the optical transient absorption spectra of RuPt compared to its monomeric $\mathrm{Ru}$ precursor (ESI section 5). For both complexes a negative band around 400-450 $\mathrm{nm}$ developing within the instrumental response time (100-15o fs) and both slightly red-shifted relative to the UV-vis absorption spectrum is observed. This signal is most likely mainly due to ground state bleach and likely also has a contribution from excited state absorption. The absence of a significant effect of the Pt moiety on the ground state bleach at early time scales after photoexcitation indicates that for RuPt Ru-based optical transitions are dominant at $527 \mathrm{~nm}$ or $532 \mathrm{~nm}$ excitation, as Pt-based excitations should have resulted in a clear change in ground state bleach. Moreover, the comparison of theoretical transient XAS data for models with weak axial coordination of Pt by the solvent, single $\mathrm{I}^{-}, \mathrm{I}_{2}^{-}$or even $\mathrm{I}_{3}^{-}$with the experimental spectra show worse agreement with the data.
Based on these arguments, we suggest that the strong oxidation process we observe is oxidative addition of $\mathrm{I}_{2}$ to the initially reduced $\mathrm{Pt}$ center, forming a hexacoordinated $\mathrm{Pt}^{\mathrm{IV}}$ complex. ${ }^{34-36}$ As a random solution mixture of 0.5-1.0 mM RuPt and reactive iodine species gives according to the Stokes-Einstein equation a diffusion time of several ns, the reactive iodine species is likely present in the RuPt solvation shell. The reduced amplitude of the difference signal (despite the strong oxidation) and the slower decay rate of the initiating species suggest additional rate-limiting processes, maybe related to $I_{2}$. The large error bars of the timescales make this argumentation however a mere suggestion that needs to be verified by additional experiments, such as $\mathrm{x}$-ray studies using the iodine edge. The general timescale of $<1$ ns for the oxidation reaction is very short, which could suggest a prior arrangement of the reacting species.

The $21 \pm 5$ ns and $340 \pm 50$ ns components observed by transient absorption (Figure $3 \mathrm{~d}$ ) and the $254 \pm 8$ ns photoluminescence decay (Figure $2 \mathrm{~b}$ ) are nearly absent in the $\mathrm{x}$-ray data, which only show a minor change between $150 \mathrm{~ns}$ and $300 \mathrm{~ns}$, and $300 \mathrm{~ns}$ and $10 \mu \mathrm{s}$. The latter difference is already present at 450 ns (data not shown). The absence of a significant change in the $\mathrm{x}$-ray spectra suggests these processes to be associated with the Ru moiety rather than the Pt catalyst. The complete excited state absorption decay (Figure 3d) indicates that the photo-oxidized $\mathrm{Ru}$ moiety is regenerated at this timescale. We cannot distinguish between the pathways leading to ground state recovery of the Ru moiety and thus have tentatively labelled the species differently. Figure 7 shows a Jablonski diagram of the proposed photoinduced processes.

The likely involvement of reactive iodine species (i.e. $\mathrm{I}^{-}, \mathrm{I}_{3}$ and/or $\mathrm{I}_{2}$ ) in the strong oxidation process following the photoinduced reduction of the $\mathrm{Pt}$ center may have important consequences for the mechanism of $\mathrm{H}_{2}$ generation. The state-of-the-art design principle of supramolecular photocatalysts is based on the use of more photons (two for $\mathrm{H}_{2}$ generation ${ }^{62}$ ) and requires accumulative charge separation. ${ }^{63}$ We activate this catalyst with a single photon, but possibly withdraw two electrons from the Pt moiety. Such an approach could thus potentially bypass the need for the highly challenging charge accumulation and should be investigated in more detail under catalytic conditions. This mechanism might also explain the generally higher photocatalytic activity of iodine-based photocatalysts relative to e.g. chloride alternatives ${ }^{64-65}$ and presents a novel paradigm for hydrogen generation by supramolecular photocatalysts. 


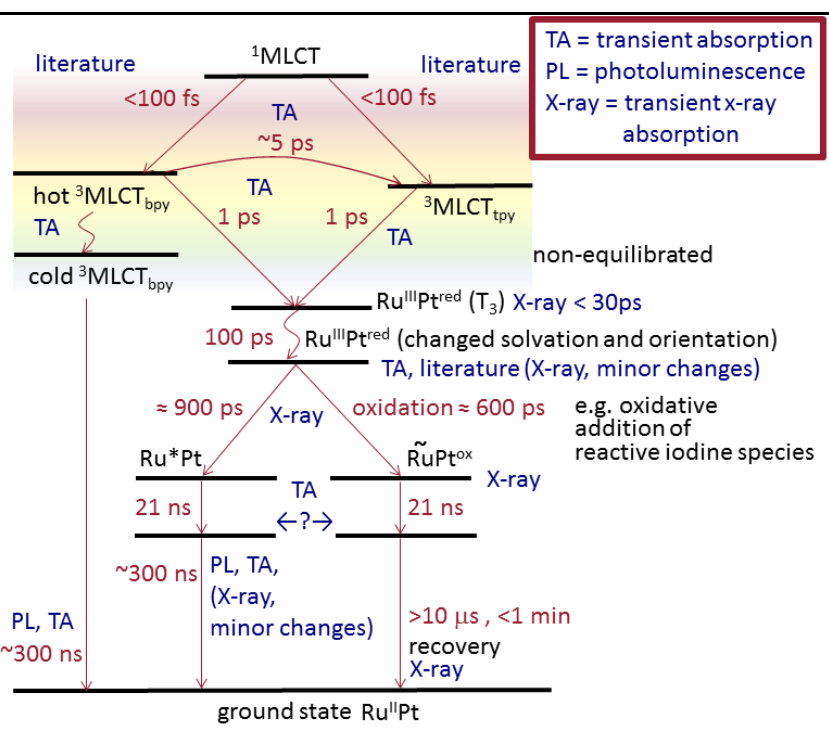

Figure 7. Jablonski diagram of processes occurring after photoexcitation of $\mathrm{RuPt}$, with the technique supporting this conclusion indicated.

\section{Conclusion}

In summary, transient optical and x-ray absorption spectroscopy studies on light-induced electronic and structural changes of a hydrogen generating supramolecular RuPt photocatalyst show that reduction of the Pt catalyst occurs at an ultrafast $<30$ ps timescale. The population of excited states is non-equilibrated at ps timescales and vibrational relaxation is competing with internal conversion towards the bridging ligand and the catalyst. Thus, not every absorbed photon leads to reduction of the $\mathrm{Pt}$ catalyst. The reduced intermediate species decays at a sub-ns timescale via two processes; a part of the complexes are strongly oxidized while a second part is returning to the ground state. The strong oxidation process may be driven by oxidative addition of reactive iodine species. The oxidized intermediate is long-lived ( $>10 \mu \mathrm{s})$ and ultimately recovers into the original ground state. This reaction scheme implies that we may withdraw two electrons from a catalyst that is activated by a single photon, bypassing the need for accumulative charge separation for $\mathrm{H}_{2}$ generation.

\section{ASSOCIATED CONTENT}

1) Models tested for difference XANES and EXAFS structure characterization.

2) FEFF parameters used for calculation of models.

3) Photoluminescence at various excitation wavelengths.

4) Differential absorbance spectra at reduction conditions.

5) Transient absorption spectra at various excitation wavelengths.

6) Time-Dependent Density Functional Theory calculations of optical transitions.
7) Comparison of white line intensity of modeled and measured XANES.

\section{AUTHOR INFORMATION}

\section{Corresponding Author}

*jens.uhlig@chemphys.lu.se

\section{Present Addresses}

$\%$ Radboud University Nijmegen, Institute for Molecules and Materials, Department of Molecular and Laser Physics, Heijendaalseweg 135, 6525 AJ, Nijmegen, The Netherlands.

\& Max Planck Institute for Polymer Research, Physics at Interfaces department, Ackermannweg 10, D-55128, Mainz, Germany.

\# ETH Zürich, Laboratory for Physical Chemistry, Vladimir Prelog Weg 1-5/10 8093 Zürich, Switzerland.

s Synchrotron SOLEIL, Science Division, Gif-sur-Yvette, Ilede-France, FR 91192.

\section{Author Contributions}

The manuscript was written through contributions of all authors. / All authors have given approval to the final version of the manuscript. $\$$ These authors contributed equally.

\section{Orchid ID}

The following authors have ORCHID ID's:

Pavel Chabera oooo-0002-0531-5138

Xiaoyi Zhang oooo-oool-9732-1449

Leon Freitag 0ooo-0002-8302-1354

Leticia González oooo-0oo1-5112-794X

Wesley R. Browne oooo-0oo1-5063-6961

Grigory Smolentsev oooo-ooo1-7348-7276

Jens Uhlig 00oo-0002-0528-0422

\section{ACKNOWLEDGMENT}

AH acknowledges support by the Dutch Sectorplan for Physics and Chemistry and the Organization for Scientific Research (NWO). Dr. Stefan C.J. Meskers (Technical University of Eindhoven, The Netherlands) is thanked for his help with the time-resolved photoluminescence experiments. Prof. Johannes G. Vos (Dublin City University, Ireland) is acknowledged for scientific discussions. JU acknowledges support by the Knut and Alice Wallenberg Stiftelse and the Carl Trygger Stiftelse. Torbjoern Pascher (Pascher Instruments, Sweden) is acknowledged for his support during the nanosecond TA experiments. GS acknowledges the Energy System Integration (ESI) platform at PSI for funding, support from NCCR MUST and the Ministry of Education and Science of the Russian Federation for the award of grant 16.3871.2017/4.6.This research used resources of the Advanced Photon Source, U.S. Department of Energy (DOE) Office of Science User Facilities operated for the DOE Office of Science by Argonne National Laboratory under Contract No. DE-ACo2-o6CH11357. 


\section{REFERENCES}

1. Lewis, N. S.; Nocera, D. G. Powering the Planet: Chemical Challenges in Solar Energy Utilization. Proceedings of the National Academy of Sciences of the United States of America 2006, 103, 15729-15735.

2. Sun, L. C.; Hammarstrom, L.; Akermark, B.; Styring, S. Towards Artificial Photosynthesis: Ruthenium-Manganese Chemistry for Energy Production. Chem. Soc. Rev. 2oo1, 30, 36-49

3. $\quad$ Magnuson, A.; Anderlund, M.; Johansson, O.; Lindblad, P.; Lomoth, R.; Polivka, T.; Ott, S.; Stensjo, K.; Styring, S.; Sundstrom, V., et al. Biomimetic and Microbial Approaches to Solar Fuel Generation. Acc. Chem. Res. 20o9, 42, 1899-1909.

4. Hammarstrom, L. Accumulative Charge Separation for Solar Fuels Production: Coupling Light-Induced Single Electron Transfer to Multielectron Catalysis. Acc. Chem. Res. 2015, 48, 840-850.

5. $\quad$ Canton, S. E.; Kjaer, K. S.; Vanko, G.; Van Driel, T. B.; Adachi, S. I.; Bordage, A.; Bressler, C.; Chabera, P.; Christensen, M.; Dohn, A. O., et al. Visualizing the Non-Equilibrium Dynamics of Photoinduced Intramolecular Electron Transfer with Femtosecond X-Ray Pulses. Nat. Commun. 2015, 6, 6359 .

6. $\quad$ Eckenhoff, W. T.; Eisenberg, R. Molecular Systems for Light Driven Hydrogen Production. Dalton Trans. 2012 , 41, 13004-13021.

7. Losse, S.; Vos, J. G.; Rau, S. Catalytic Hydrogen Production at Cobalt Centres. Coord. Chem. Rev. 2010, 254, 2492-2504.

8. Probst, B.; Kolano, C.; Hamm, P.; Alberto, R. An Efficient Homogeneous Intermolecular Rhenium-Based Photocatalytic System for the Production of H-2. Inorg. Chem. 2oo9, 48, 1836-1843.

9. Ozawa, H.; Haga, M.; Sakai, K. A Photo-Hydrogen-Evolving Molecular Device Driving Visible-Light-Induced Edta-Reduction of Water into Molecular Hydrogen. J. Am. Chem. Soc. 20o6, 128, 4926-4927.

10. Rau, S.; Schafer, B.; Gleich, D.; Anders, E.; Rudolph, M.; Friedrich, M.; Gorls, H.; Henry, W.; Vos, J. G. A Supramolecular Photocatalyst for the Production of Hydrogen and the Selective Hydrogenation of Tolane. Angew. Chem. Int. Ed. 2006, 45, 6215-6218.

11. Bressler, C.; Milne, C.; Pham, V. T.; Elnahhas, A.; Van Der Veen, R. M.; Gawelda, W.; Johnson, S.; Beaud, P.; Grolimund, D.; Kaiser, M., et al. Femtosecond Xanes Study of the Light-Induced Spin Crossover Dynamics in an Iron(Ii) Complex. Science 2oog, 323, 489-492.

12. Smolentsev, G.; Sundstrom, V. Time-Resolved X-Ray Absorption Spectroscopy for the Study of Molecular Systems Relevant for Artificial Photosynthesis. Coord. Chem. Rev. 2015, 304, 117-132.

13. Mara, M. W.; Fransted, K. A.; Chen, L. X. Interplays of Excited State Structures and Dynamics in Copper(I) Diimine Complexes: Implications and Perspectives. Coord. Chem. Rev. 2015, 282, 2-18.

14. $\quad$ Chábera, P.; Liu, Y.; Prakash, O.; Thyraug, E.; El Nahhas, A.; Honarfar, A.; Essén, S.; Fredin, L. A.; Harlang, T. C. B.; Kjær, K. S., et al. A Low-Spin Fe(Iii) Complex with 100 Ps Ligand-to-Metal Charge Transfer Photoluminescence. Nature 2017, 543, 695 -699.

15. Hayes, D.; Kohler, L.; Hadt, R. G.; Zhang, X.; Liu, C.; Mulfort, K. L.; Chen, L. X. Excited State Electron and Energy Relays in Supramolecular Dinuclear Complexes Revealed by Ultrafast Optical and X-Ray Transient Absorption Spectroscopy. Chem. Sci. 2018, 9, 86o-875

16. Van Driel, T. B.; Kjær, K. S.; Hartsock, R. W.; Dohn, A. O.; Harlang, T.; Chollet, M.; Christensen, M.; Gawelda, W.; Henriksen, N. E.; Kim, J. G., et al. Atomistic Characterization of the Active-Site Solvation Dynamics of a Model Photocatalyst. Nat. Commun. 2016, 7, 13678.

17. Ponseca, C. S.; Chábera, P.; Uhlig, J.; Persson, P.; Sundström, V. Ultrafast Electron Dynamics in Solar Energy Conversion. Chem. Rev. 2017, 117, 10940-11024.

18. Chen, L. X.; Jager, W. J. H.; Jennings, G.; Gosztola, D. J.; Munkholm, A.; Hessler, J. P. Capturing a Photoexcited Molecular Structure through Time-Domain X-Ray Absorption Fine Structure. Science 2001, 292, 262-264.

19. Chen, L. X. Taking Snapshots of Photoexcited Molecules in Disordered Media by Using Pulsed Synchrotron X-Rays. Angew. Chem. Int. Ed. 2004, 43, 2886-2905.

20. Saes, M.; Bressler, C.; Abela, R.; Grolimund, D.; Johnson, S. L.; Heimann, P. A.; Chergui, M. Observing Photochemical Transients by Ultrafast X-Ray Absorption Spectroscopy. Phys. Rev. Lett. 2003, 9o, 047403.

21. Chergui, M.; Collet, E. Photoinduced Structural Dynamics of Molecular Systems Mapped by Time-Resolved X-Ray Methods. Chem. Rev. $2017,117,11025-11065$.

22. Smolentsev, G.; Cecconi, B.; Guda, A.; Chavarot-Kerlidou, M.; Van Bokhoven, J. A.; Nachtegaal, M.; Artero, V. Microsecond X-Ray Absorption Spectroscopy Identification of Co-I Intermediates in Cobaloxime-Catalyzed Hydrogen Evolution. Chem. Eur. J. 2015, 21, 15158-15162.

23. Moonshiram, D.; Gimbert-Suriñach, C.; Guda, A.; Picon, A.; Lehmann, C. S.; Zhang, X.; Doumy, G.; March, A. M.; Benet-Buchholz, J.; Soldatov, A., et al. Tracking the Structural and Electronic Configurations of a Cobalt Proton Reduction Catalyst in Water. J. Am. Chem. Soc. 2o16, $138,10586-10596$.

24. $\quad$ Li, Z.-J.; Zhan, F.; Xiao, H.; Zhang, X.; Kong, Q.-Y.; Fan, X.-B.; Liu, W.-Q.; Huang, M.-Y.; Huang, C.; Gao, Y.-J., et al. Tracking Co(I) Intermediate in Operando in Photocatalytic Hydrogen Evolution by X-Ray Transient Absorption Spectroscopy and Dft Calculation. J. Phys. Chem. Lett. 2016, 7, 5253-5258.

25. $\quad$ Kowacs, T.; O'Reilly, L.; Pan, Q.; Huijser, A.; Lang, P.; Rau, S.; Browne, W. R.; Pryce, M. T.; Voss, J. G. Subtle Changes to Peripheral Ligands Enable High Turnover Numbers for Photocatalytic Hydrogen Generation with Supramolecular Photocatalysts. Inorg. Chem. 2016, 55, 26852690.

26. Pan, Q.; Mecozzi, F.; Korterik, J. P.; Vos, J. G.; Browne, W. R.; Huijser, A. The Critical Role Played by the Catalytic Moiety in the EarlyTime Photodynamics of Hydrogen Generating Bimetallic Photocatalysts. ChemPhysChem 2016, 17, $2654-2659$.

27. Tschierlei, S.; Karnahl, M.; Presselt, M.; Dietzek, B.; Guthmuller, J.; Gonzalez, L.; Schmitt, M.; Rau, S.; Popp, J. Photochemical Fate: The First Step Determines Efficiency of H-2 Formation with a Supramolecular Photocatalyst. Angew. Chem. Int. Ed. 2010, 49, 3981-3984.

28. Pan, Q.; Freitag, L.; Kowacs, T.; Falgenhauer, J. C.; Korterik, J. P.; Schlettwein, D.; Browne, W. R.; Pryce, M. T.; Rau, S.; Gonzalez, L., et al. Peripheral Ligands as Electron Storage Reservoirs and Their Role in Enhancement of Photocatalytic Hydrogen Generation. Chem. Commun. 2o16, 52, 9371-9374.

29. Pan, Q.; Mecozzi, F.; Korterik, J. P.; Sharma, D.; Herek, J. L.; Vos, J. G.; Browne, W. R.; Huijser, A. Directionality of Ultrafast Electron Transfer in a Hydrogen Evolving Ru-Pd-Based Photocatalyst. J. Phys. Chem. C 2014, 118, 20799-20806.

30. Bhasikuttan, A. C.; Okada, T. Excited-State Relaxation Dynamics of Ru(Dcbpy)2(Ncs)2, Studied by Fluorescence Upconversion Spectroscopy. J. Phys. Chem. B 2004, 108, 12629-12632.

31. Hartley, F. R., The Chemistry of Platinum and Palladium: With Particular Reference to Complexes of the Elements; Applied Science Publishes, 1973.

32. Williams, J. A. G., Photochemistry and Photophysics of Coordination Compounds: Platinum, 2007 ; Vol. 281, p 205-268.

33. Bindra, G. S.; Schulz, M.; Paul, A.; Groarke, R.; Soman, S.; Inglis, J. L.; Browne, W. R.; Pfeffer, M. G.; Rau, S.; Maclean, B. J., et al. The Role 
of Bridging Ligand in Hydrogen Generation by Photocatalytic Ru/Pd Assemblies. Dalton Trans. 2012, 41, 13050-13059.

34. Ha, K. Crystal Structure of (Acetonitrile-N)Chlorido[2-(2-Pyridyl)Phenyl-2n,C] Platinum(Ii), C13hinclnzpt. Z. Kristallogr. - New Cryst. Struct. 2014, 229, 151-152.

35. Miller, J. S.; Min, K. S. Oxidation Leading to Reduction: Redox-Induced Electron Transfer (Riet). Angew. Chem. Int. Ed. 20o9, 48, 262-

272.

36. Nabavizadeh, S. M.; Amini, H.; Rashidi, M.; Pellarin, K. R.; Mccready, M. S.; Cooper, B. F. T.; Puddephatt, R. J. The Mechanism of Oxidative Addition of Iodine to a Dimethylplatinum(Ii) Complex. J. Organomet. Chem. 2012, 713, 6o-67.

37. Canton, S. E.; Zhang, X. Y.; Zhang, J. X.; Van Driel, T. B.; Kjaer, K. S.; Haldrup, K.; Chabera, P.; Harlang, T.; Suarez-Alcantara, K.; Liu, Y. Z., et al. Toward Highlighting the Ultrafast Electron Transfer Dynamics at the Optically Dark Sites of Photocatalysts. J. Phys. Chem. Lett. 2013, 4, 1972-1976.

38. $\quad$ Snellenburg, J. J.; Laptenok, S. P.; Seger, R.; Mullen, K. M.; Van Stokkum, I. H. M. Glotaran: A Java-Based Graphical User Interface for the R Package Timp. J. Stat. Softw. 2012, 49, 1-22.

39. Jones, E.; Oliphant, T.; Peterson, P.; Others Scipy: Open Source Scientific Tools for Python. http://www.scipy.org/ (accessed 2017-Dec-

15).

40. $\quad$ Oang, K. Y.; Yang, C.; Muniyappan, S.; Kim, J.; Ihee, H. Svd-Aided Pseudo Principal-Component Analysis: A New Method to Speed up and Improve Determination of the Optimum Kinetic Model from Time-Resolved Data. Struc. Dyn. 2017, 4, 044013.

41. Ruckebusch, C.; Sliwa, M.; Pernot, P.; De Juan, A.; Tauler, R. Comprehensive Data Analysis of Femtosecond Transient Absorption Spectra: A Review. J. Photochem. Photobiol., C 2012, 13, 1-27.

42. Van Stokkum, I. H. M.; Larsen, D. S.; Van Grondelle, R. Global and Target Analysis of Time-Resolved Spectra. Biochim. Biophys. Acta, Bioenerg. 2004, 1657, 82-104.

43. Ravel, B.; Newville, M. Athena, Artemis, Hephaestus: Data Analysis for X-Ray Absorption Spectroscopy Using Ifeffit. J. Synchrotron Radiat. 2005, 12, 537-541.

44. Bunker, G., Introduction to Xafs-a Practical Guide to X-Ray Absorption Fine Structure Spectroscopy; Cambridge University Press, 2010.

45. Calvin, S., Xafs for Everyone; CRC Press, 2013

46. Rehr, J. J.; Kas, J. J.; Vila, F. D.; Prange, M. P.; Jorissen, K. Parameter-Free Calculations of X-Ray Spectra with Feff9. PCCP 2010, 12, 5503-

5513.

47. Smolentsev, G.; Soldatov, A. V. Fitit: New Software to Extract Structural Information on the Basis of Xanes Fitting. Comput. Mater. Sci. 2007, 39, 569-574.

48. Seabold, J. S.; Perktold, J. In Statsmodels: Econometric and Statistical Modeling with Python, Proceedings of the 9th Python in Science Conference, 2010

49. Kobayashi, M.; Masaoka, S.; Sakai, K. Syntheses, Characterization, and Photo-Hydrogen-Evolving Properties of Tris(2,2'Bipyridine)Ruthenium(Ii) Derivatives Tethered to an H2-Evolving (2-Phenylpyridinato)Platinum(Ii) Unit. Molecules 2010, 15, $4908-4923$.

50. Damrauer, N. H.; Cerullo, G.; Yeh, A.; Boussie, T. R.; Shank, C. V.; Mccusker, J. K. Femtosecond Dynamics of Excited-State Evolution in $[\mathrm{Ru}(\mathrm{Bpy})(3)](2+)$. Science 1997, 275, 54-57.

51. Cannizzo, A.; Van Mourik, F.; Gawelda, W.; Zgrablic, G.; Bressler, C.; Chergui, M. Broadband Femtosecond Fluorescence Spectroscopy of [Ru(Bpy)(3)](2+). Angew. Chem. Int. Ed. 20o6, 45, 3174-3176.

52. Atkins, A. J.; González, L. Trajectory Surface-Hopping Dynamics Including Intersystem Crossing in [Ru(Bpy)3]2+. J. Phys. Chem. Lett. $2017,8,3840-3845$.

53. Battocchio, C.; D’acapito, F.; Smolentsev, G.; Soldatov, A. V.; Fratoddi, I.; Contini, G.; Davoli, I.; Polzonetti, G.; Mobilio, S. Xas Study of a Pt-Containing Rod-Like Organometallic Polymer. Chem. Phys. 2006, 325, 422-428.

54. Lockard, J. V.; Rachford, A. A.; Smolentsev, G.; Stickrath, A. B.; Wang, X. H.; Zhang, X. Y.; Atenkoffer, K.; Jennings, G.; Soldatov, A.; Rheingold, A. L., et al. Triplet Excited State Distortions in a Pyrazolate Bridged Platinum Dimer Measured by X-Ray Transient Absorption Spectroscopy. J. Phys. Chem. A 2010, 114, 12780-12787.

55. $\quad$ Tsai, Y. W.; Tseng, Y. L.; Sarma, L. S.; Liu, D. G.; Lee, J. F.; Hwang, B. J. Genesis of Pt Clusters in Reverse Micelles Investigated by in Situ X-Ray Absorption Spectroscopy. J. Phys. Chem. B 2004, 108, 8148-8152.

56. Hall, M. D.; Foran, G. J.; Zhang, M.; Beale, P. J.; Hambley, T. W. Xanes Determination of the Platinum Oxidation State Distribution in Cancer Cells Treated with Platinum(Iv) Anticancer Agents. J. Am. Chem. Soc. 2003, 125, 7524-7525.

57. Yahav, A.; Goldberg, I.; Vigalok, A. Iodine Oxidative Addition to Isomeric Platinum(Ii) Phosphine Complexes. Organometallics 2005, 24, 5654-5659.

58. Van Beek, J. A.; Van Koten, G.; Smeets, W. J.; Spek, A. L. Model for the Initial Stage in the Oxidative Addition of I2 to Organoplatinum (Ii) Compounds. X-Ray Structure of Square-Pyramidal [Ptiii \{C6h3 (Ch2nmez) 2-O, O'\}(. Eta. 1-I2)] Containing a Linear Pt-Ii Arrangement. J. Am. Chem. Soc. 1986, 108, 5010-5011.

59. $\quad$ Gossage, R. A.; Ryabov, A. D.; Spek, A. L.; Stufkens, D. J.; Van Beek, J. A.; Van Eldik, R.; Van Koten, G. Models for the Initial Stages of Oxidative Addition. Synthesis, Characterization, and Mechanistic Investigation of H1-I2 Organometallic "Pincer" Complexes of Platinum. X-Ray Crystal Structures of [Pti (C6h3 $\left\{\mathrm{Ch}_{2} \mathrm{nmme}_{2}\right\}$ 2-2, 6)(H1-I2)] and Exo-Meso-[Pt (H1-I3)(H1-I2)(C6h3 \{Ch2n (T-Bu) Me\} 2-2, 6)]. J. Am. Chem. Soc. 1999, 121, 2488-2497.

6o. $\quad$ Suneesh, C. V.; Balan, B.; Ozawa, H.; Nakamura, Y.; Katayama, T.; Muramatsu, M.; Nagasawa, Y.; Miyasaka, H.; Sakai, K. Mechanistic Studies of Photoinduced Intramolecular and Intermolecular Electron Transfer Processes in Rupt-Centred Photo-Hydrogen-Evolving Molecular Devices. PCCP 2014, 16, 1607-1616.

61. Kobayashi, M.; Masaoka, S.; Sakai, K. Synthesis, Crystal Structure, Solution and Spectroscopic Properties, and Hydrogen-Evolving Activity of [K(18-Crown-6)][Pt(Ii)(2-Phenylpyridinato)Cl2]. Photochem. Photobiol. Sci. 2009, 8, 196-203.

62. $\quad$ Kowacs, T.; Pan, Q.; Lang, P.; O'reilly, L.; Rau, S.; Browne, W. R.; Pryce, M. T.; Huijser, A.; Vos, J. G. Supramolecular Bimetallic Assemblies for Photocatalytic Hydrogen Generation from Water. Faraday Discuss. 2015, 185, 143-170.

63. Hammarström, L. Accumulative Charge Separation for Solar Fuels Production: Coupling Light-Induced Single Electron Transfer to Multielectron Catalysis. Acc. Chem. Res. 2015, 48, 840-850.

64. Pfeffer, M. G.; Schäfer, B.; Smolentsev, G.; Uhlig, J.; Nazarenko, E.; Guthmuller, J.; Kuhnt, C.; Wächtler, M.; Dietzek, B.; Sundström, V., et al. Palladium Versus Platinum: The Metal in the Catalytic Center of a Molecular Photocatalyst Determines the Mechanism of the Hydrogen Production with Visible Light. Angew. Chem. Int. Ed. 2015, 54, 5044-5044.

65. Pfeffer, M. G.; Kowacs, T.; Wächtler, M.; Guthmuller, J.; Dietzek, B.; Vos, J. G.; Rau, S. Optimization of Hydrogen-Evolving Photochemical Molecular Devices. Angew. Chem. Int. Ed. 2015, 54, 6627-6631. 


\section{TOC Graphic}

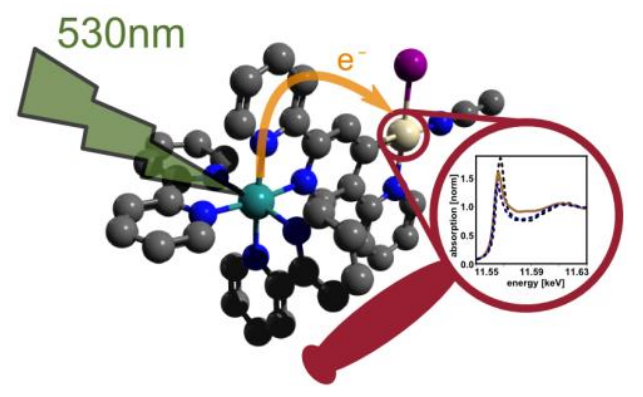

